\title{
FOOD SAFETY RESEARCH AT A TIME OF NATIONAL EMERGENCY
}

\author{
Curtis L. Kastner \\ Director, Food Science Institute \\ Kansas State University
}

\section{Introduction}

My objective is to summarize food safety research at Kansas State University and to relate how that research addresses agricultural biosecurity challenges in the nation.

Particularly since September 11, 2001, it is imperative to develop strategies of preparedness. It is obvious that terrorists are motivated and they have been effective in achieving their goals. The logical response strategies include being prepared to: prevent terrorism if possible, and respond in a systematic way to minimize the impact. The attacks caused immediate loss of life, and also set off a cascade of events with long-term implications that are psychological, social, environmental, economic, and public health related. The challenge is to be prepared and to minimize the consequences of terrorism.

The U.S. food production and processing industries are as vulnerable as any target and must be protected. Even though attacks on the food supply might be less likely to result in immediate loss of life when compared to direct attacks, the outcomes are similar. Disruption of the food supply and loss of consumer confidence would have devastating impacts on public health, social order, and domestic and international markets. Terrorists have identified the U.S. food supply as a viable, vulnerable target. Therefore, attacks on the food supply must be prevented if possible, or systematically addressed to minimize the impact.

Protecting America's food supply and associated agricultural infrastructure from deliberate acts of bioterrorism is of paramount importance to the U.S. and world economies. America's agribusiness sector routinely provides more than $\$ 1$ trillion annually to the U.S. economy, nearly $15 \%$ of the Gross Domestic Product. Assault on this sector of the economy could be catastrophic.

The recent Foot and Mouth Disease (FMD) outbreak in Great Britain illustrates the potential economic costs of an attack on America's food crop, food animal, or food processing industry. The losses in Great Britain have been calculated at $\$ 25$ billion and have crippled a once-robust industry. Along with Bovine Spongiform Encephalopathy (BSE), it has virtually destroyed British consumer confidence in the safety of red meat and in their government's 
oversight capabilities. While BSE has not yet occurred in the U.S., it is of great concern.

With concentrated and intensive production practices that help feed the world, the cost of a successful bioterrorist attack would certainly dwarf Great Britain's economic devastation. In addition to a compromised U.S. economy, the shockwaves of a significant attack would certainly have global implications. Immediate losses in the tens of billions of dollars could be counted in days or hours, as trade sanctions and embargos would quickly follow. Loss of consumer confidence and compromised public health would ravage an already shaky economy.

Food safety research is not new. Processes such as canning of meats, pasteurization of milk, and irradiation of pork have already been researched and brought to application for the purpose of addressing food safety issues. Food safety research efforts continue to capitalize on those historical as well as new technologies, and apply them in unique ways to address today's food safety challenges. Incidents such as the 1993 Jack-in-the Box E coli 0157:H7 outbreak intensified the focus on food safety. Until the events of September 2001, research did not emphasize the potential for intentionally caused food safety incidents. Even though we have examples of this problem, the focus has been on incidental food safety challenges. Nonetheless the strategies used to address incidental food safety events are transferable to intentionally caused events.

\section{Meat Safety Research}

Meat safety research at Kansas State University is an excellent model for using food safety strategies to address national biosecurity challenges.

The best way to achieve food safety is by working with the continuum of meat production from farm to fork as a total system. The approach is to make, for example, incremental pathogen reductions from the live animal level all the way to the carcass and then to the individual meat cut that goes to the consumer. For example, strategies to reduce pathogens in drinking water at the feedlot, steam pasteurization of carcasses, and precooking of the individual meat item all contribute to the ultimate safety of the product. Incremental pathogen bio-load reduction along the continuum of production and processing results in a safe product. That same strategy can be used to address events whether incidental or intentional. The points at which hazards can be reduced pre- as well as postharvest, and the technologies to eliminate hazards are the same whether incidentally or intentionally introduced.

Pre-harvest food safety practices that reduce hazardous exposures to the animal include treatment of water and feed to reduce exposure to pathogenic bacteria. Physical protection and treatment of those feedlot consumables will also be required in a biosecurity system that addresses bioterrorism threats. 
Those reductions can then be coupled with carcass steam pasteurization and chemical treatments plus treatment of the end product by using, for example, post-process steam pasteurization. Those and other strategies can be used to address bioterrorism issues.

Another strategy involves combining more than one intervention in the food processing chain. A good example is the use of steam pasteurization of beef carcasses followed by post-process, in-package steam pasteurization. Steam pasteurization of beef carcasses greatly reduces pathogen contamination on the surface of the carcass. However, upon subsequently handling, some pathogens could be reintroduced. Therefore, additional control of pathogens is required. The post-process, in-package steam pasteurization intervention technology eliminates pathogens on the surface of ready-to-eat (RTE) meat products. The steam-based, post-process pasteurization system is effective in reducing pathogen populations on the surfaces of frankfurters and can be used in the manufacture of frankfurters and similar RTE meat products. The process does not result in significant deterioration in quality due to secondary heat exposure of the RTE meat surfaces and could improve the shelf life of these products. The effectiveness of the system could be improved by incorporating bacteriostatic agents (i.e. lactic acid) either as a topical application or as an ingredient in the RTE meat formulations to reduce the risk or recovery of the sublethally injured organisms during subsequent refrigerated storage during commercial distribution and by the consumers at home. By combining intervention strategies, food safety is enhanced and the process addresses pathogen contamination regardless of where or how it is introduced.

\section{Summary and Conclusions}

Terrorism can take a variety of forms, including attacks on our agricultural and food systems. Attacks on the food supply would likely be less dramatic as compared to a nuclear attack. However, the impact on consumer confidence, export markets, food cost, and the economy would be significant. Some terrorists are willing to sacrifice their lives and take human life; more may be willing to perform acts that do not take their lives and primarily impact our economic infrastructure. Some hazards impact only the animal or crop whereas others impact humans as well. To completely prevent terrorist attacks is impossible. Therefore, the strategy is to be prepared so that the impact is minimized. Food safety research has generated strategies that can significantly help minimize the impact of terrorism. Whether a hazard is incidentally or intentionally introduced, we have interventions that can be used to eliminate hazards. In the face of terrorism we must couple what we already know with strategies specifically focused on terrorism. For example, physical protection and intervention strategies used by the military can be combined with our food safety know how.

Fortunately, food safety research has provided information and technologies we need to address our national bioterrorism emergency. With the 
legislative approval of the new biosafety research facility at Kansas State University and our designation as the National Agricultural Biosecurity Center, we will be better equipped to address each aspect of bioterrorism that includes crops, animals and food from those sources. 